\title{
Ensemble coding in the nucleus accumbens
}

\author{
PATRICIO O'DONNELL \\ Albany Medical College, Albany, New York
}

\begin{abstract}
The nucleus accumbens may be involved in cognitive functions via its control of thalamocortical activity feeding back to the prefrontal cortex. Functional neuronal ensembles, or changes in the spatial and temporal distribution of active and inactive neurons, may mediate information processing in the accumbens. Neurons are considered active during the plateau depolarizations, or up state, that most nucleus accumbens neurons exhibit. Action potential firing can occur only during these events in these neurons. Inputs controlling the distribution and timing of up events (i.e., limbic afferents and dopamine) may determine the spatiotemporal pattern of accumbens neuronal ensembles and, therefore, of thalamoprefrontal cortical activity.
\end{abstract}

Cognitive functions have been attributed to the nucleus accumbens (NAcc) for some time, although the precise nature of its involvement remains unknown. Indeed, the ventral striatum has been recently defined as a cognitive pattern generator (Graybiel, 1997). Pennartz, Groenewegen, and Lopes da Silva (1994) have proposed that NAcc functions are based on the organization of neuronal ensembles. Connectivity patterns in different subterritories of the NAcc can determine the spatial distribution of neurons that can be linked in an ensemble. However, these ensembles need to be adaptable to a changing complex environment. Thus, for them to be relevant to behavior, they should also rely on functional properties of NAcc neurons rather than on just its hardwiring. This would be similar to what in the hippocampus has been referred to as ensemble coding (Eichenbaum, Wiener, Shapiro, \& Cohen, 1989; M. A. Wilson \& McNaughton, 1993). Here, I present a theoretical model on the modulation of information processing in the NAcc based on previous experimental work that can account for ensemble coding. The spatial and temporal distribution of active and inactive neurons can be established and reinforced by several inputs, yielding to dynamic ensembles of NAcc neurons that may account for its role in controlling prefrontal cortex (PFC) cognitive functions.

Evidence supporting an involvement of the NAcc in cognition has been obtained from several lines of research. Behavioral studies have shown NAcc neurons firing in relation to reward (Apicella, Ljungberg, Scarnati, \& Schultz, 1991; Schultz, Apicella, Scarnati, \& Ljungberg, 1992; Shidara, Aigner, \& Richmond, 1998). Suppression of NAcc activity by either a lesion or an application of local anesthetics impairs a number of behaviors, including prepulse inhibition of the acoustic startle response

This work was supported by National Institute of Mental Health Grant MH57683. Correspondence should be addressed to P. O'Donnell, Department of Pharmacology and Neuroscience, Albany Medical College (A-136), 47 New Scotland Ave., Albany, NY 12208 (e-mail: patricio.o'donnell@ccgateway.amc.edu).
(Kodsi \& Swerdlow, 1997), hoarding (Stern \& Passingham, 1994), spatial learning (Annett, McGregor, \& Robbins, 1989), food intake patterns (Clifton \& Somerville, 1994), memory (Gal, Joel, Gusak, Feldon, \& Weiner, 1997; Seamans \& Phillips, 1994), and switching strategies in different tasks (Gal et al., 1997; Reading \& Dunnett, 1991), among many others. Furthermore, manipulations of transmitters in the NAcc alter social recognition (Ploeger, Willemen, \& Cools, 1991), exploratory locomotion (Floresco, Seamans, \& Phillips, 1997; MaldonadoIrizarry \& Kelley, 1994; Mogenson \& Wu, 1991 a, 1991b), learning paradigms (Chu \& Kelley, 1992; MaldonadoIrizarry \& Kelley, 1995; Westbrook, Good, \& Kiernan, 1997), latent inhibition (or the ability to ignore irrelevant stimuli; Solomon \& Staton, 1982), prepulse inhibition (Wan, Geyer, \& Swerdlow, 1994; Wan \& Swerdlow, 1993, 1996), feeding and oral behaviors (Maldonado-Irizarry, Swanson, \& Kelley, 1995; Prinssen, Balestra, Bemelmans, \& Cools, 1994), reward-related behaviors (Chu \& Kelley, 1992), and the responses to a novel environment (Hooks $\&$ Kalivas, 1995). Several of these behaviors may also be attributed to prefrontal cortical function (Fuster, 1997). Thus, given the organization of circuits in which the NAcc participates (Groenewegen \& Berendse, 1994; O'Donnell, Lavín, Enquist, Grace, \& Card, 1997), at least some of NAcc functions may be mediated via its involvement in reentrant circuits controlling PFC activity.

\section{INTEGRATION OF INFORMATION IN THE NUCLEUS ACCUMBENS}

The connectivity pattern of the NAcc allows for the integration of cognitive and emotion-related inputs to control PFC activity. The NAcc can control thalamo-PFC activity by way of its projections to the ventral pallidum (VP) and substantia nigra (Figure 1; O'Donnell et al., 1997; Zahm, Williams, \& Wohltmann, 1996). The NAcc receives converging inputs from a variety of limbic structures, including the hippocampus and amygdala (Finch, 1996; Groenewegen et al., 1991; O'Donnell \& Grace, 1995). 


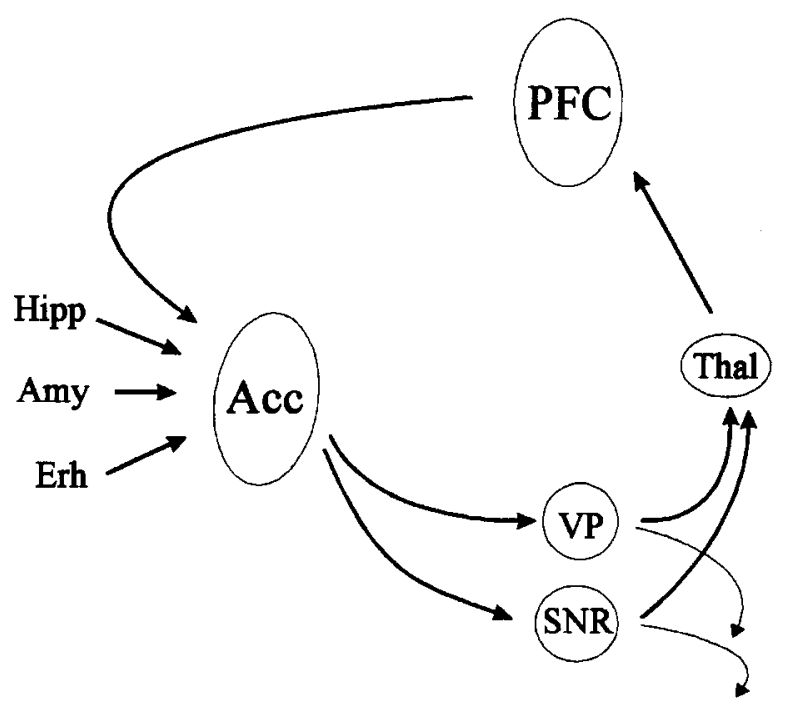

Figure 1. Schematic organization of circuits including the nucleus accumbens that underlie its control of prefrontal cortical activity. Circles represent structures involved in such circuits. The nucleus accumbens receives glutamatergic projections from a variety of neocortical and allocortical areas, including the medial and orbital prefrontal cortices (PFC), hippocampal formation (Hipp), amygdala (Amy), and entorhinal cortex (Erh). Its efferent projection targets primarily the ventral pallidum (VP) and substantia nigra pars reticulata (SNR). Pallidal and nigral neurons project to several different targets. Those relevant to PFC function include the mediodorsal and reticular thalamic nuclei (Thal).

The information provided by these afferents (i.e., contextual and spatial from the hippocampus, emotional from the amygdala) may interact with that arriving from the PFC. The outcome of these interactions within the NAcc controls VP inhibition of the thalamo-PFC system and determines the level and distribution of activity in mediodorsal (MD) thalamic neurons projecting to the PFC.

These interactions are based on physiological properties of NAcc neurons. The majority of output neurons in the NAcc exhibit a bistable membrane potential, characterized by an alternation between a very polarized resting membrane potential (down state) and depolarized plateaus (up state) (O'Donnell \& Grace, 1995). This phenomenon has also been observed in dorsal striatal medium spiny neurons (Calabresi, Mercuri, Stefani, \& Bernardi, 1990; C. J. Wilson \& Groves, 1981; C. J. Wilson \& Kawaguchi, 1996); in both the ventral and the dorsal striatum, the down state is considered the resting membrane potential, whereas the up state depends on synaptic input activity (O'Donnell \& Grace, 1995; C. J. Wilson \& Kawaguchi, 1996). Up events can only be observed using in vivo intracellular recordings, whereas in vitro intracellular recordings yield neurons with membrane potentials within the range of the down state (O'Donnell \& Grace, 1993). In the NAcc, up events are dependent on the integrity of hippocampal afferents, as shown by the inability to record bistable neurons in rats bearing a fimbria-fornix transec- tion or by the temporary suppression of up events following lidocaine injection into the fimbria-fornix (O'Donnell \& Grace, 1995). During the down state, firing threshold is $25-30 \mathrm{mV}$ from resting potential; thus, $\mathrm{PFC}$-originated synaptic responses are unlikely to result in action potential firing (Figure 2; O'Donnell \& Grace, 1995). On the other hand, during the hippocampal-driven up state, the membrane potential is so close to firing threshold that even a small-amplitude excitatory postsynaptic potential (EPSP) from cortical afferent activation may be able to result in action potential firing (Figure 2; O'Donnell \& Grace, 1995). We have interpreted these results as contextsensitive hippocampal input gating PFC throughput in the nucleus accumbens. Up events can be considered then as active periods, or windows of opportunity during which relatively discrete excitatory inputs to the NAcc can yield spike firing. The spontaneous firing observed during the up state (O'Donnell \& Grace, 1995) could be attributed to the arrival of such inputs. The role of other limbic afferents, such as those originating in the amygdala or entorhinal cortex, on up events of NAcc neurons remains to be addressed.

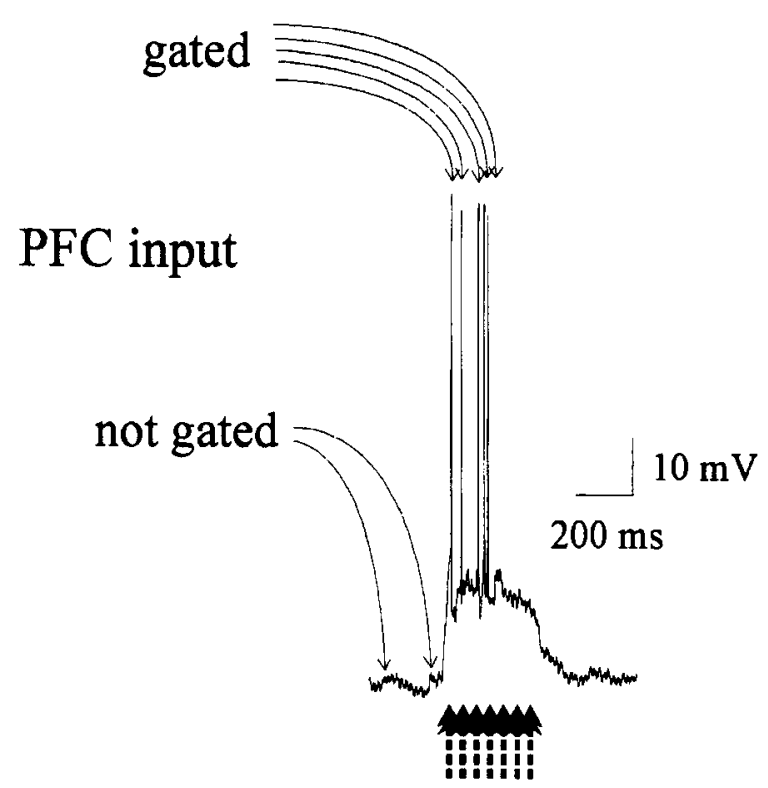

Figure 2. Most nucleus accumbens neurons exhibit a bistable membrane potential. During the down state, synaptic responses to cortical afferent activation are relatively small and do not result in action potential firing. This representative tracing shows an up event from a nucleus accumbens neuron. Small spontaneous EPSPs are indicated with the arrows labeled "not gated" during the down state $(-79 \mathrm{mV})$. The up state $(-65 \mathrm{mV})$ is dependent on hippocampal inputs (represented by broken upward arrows underneath the tracing), and cortical afferent activity may yield action potential firing only during this period. This is due to the relative proximity of the up state to firing threshold. Action potentials in the tracing are occurring spontaneously, but they are probably due to synaptic responses that do not require large amplitude to reach firing threshold. They are indicated with the arrows labeled "gated." 


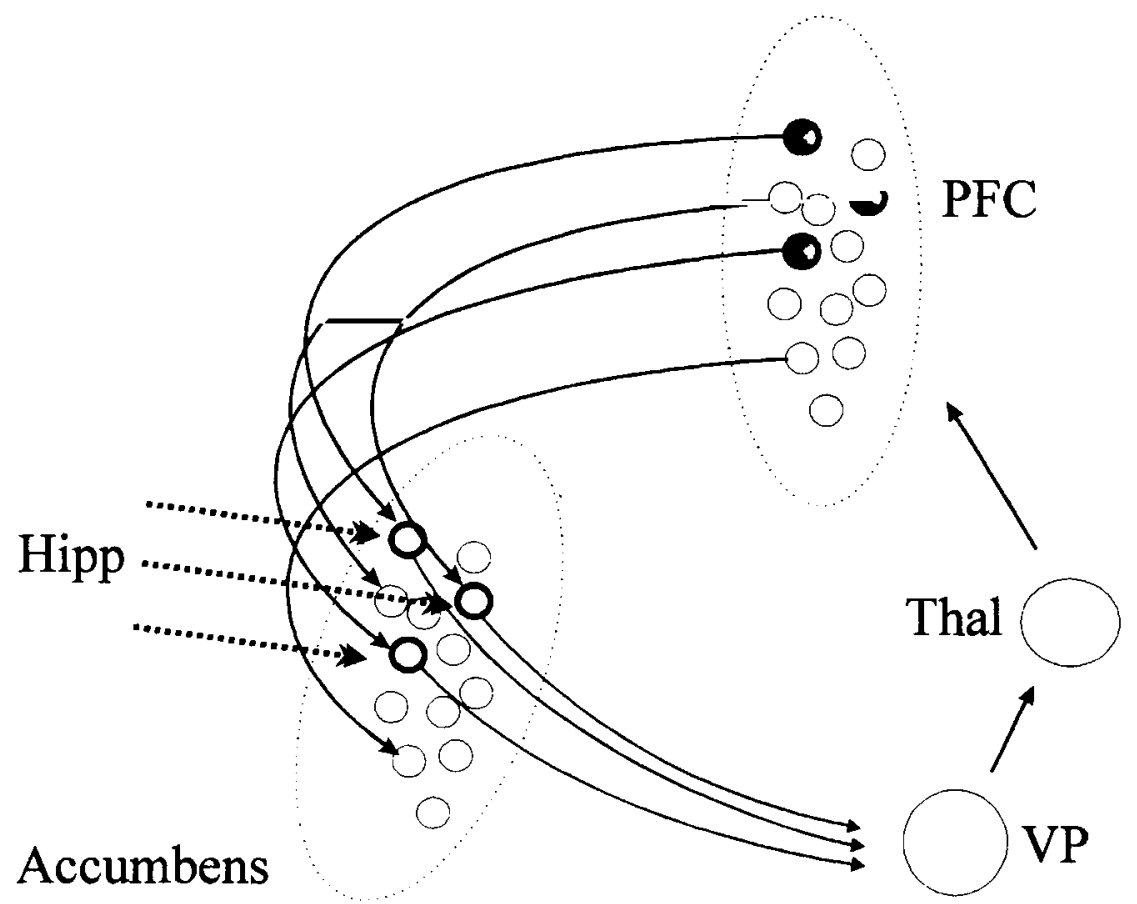

Figure 3. Hippocampal gating of prefrontal cortical throughput in the nucleus accumbens is essential to establish ensembles of active neurons. By putting neurons in their up state (thick open circles; thin circles represent neurons in the down state), hippocampal inputs (broken arrows) translate contextual and spatial information into a pattern of neuronal activity in the nucleus accumbens. By way of accumbal projections to the ventral pallidum (VP) and substantia nigra, and from there to the mediodorsal thalamic nucleus (Thal) and prefrontal cortex ( $P F C)$, the distribution of active cells in the nucleus accumbens defines the activation of PFC. This results in the selection of the appropriate ensemble in the PFC, shown as shadowed circles.

The spatial distribution of up events in the NAcc determines the topology of thalamocortical activity controlling the PFC. According to the context, there will be a different set of NAcc neurons in their up, or active, state; NAcc information to the VP-thalamocortical system can only arise from neurons in their up state (Figure 2). Thus, the factors controlling which cells are up or down and the timing of their transitions will control thalamocortical activation of the PFC. The distribution of NAcc neurons in the up state at any given moment may determine the spatial distribution of active thalamocortical units driving PFC cell firing (Figure 3 ). In this way, ensemble coding in the NAcc may command the neuronal ensembles in the PFC.

The temporal pattern of up events is also important. To establish a spatially distributed ensemble of active neurons, the synchrony of up events may be more relevant than single action potential synchronization (Figure 4). By bringing the membrane potential of selected units close to firing threshold, up events may be the behaviorally relevant factors determining cell activity in the NAcc; actual cell firing is then a matter of probabilities during up events. There are at least two potential sources of up-event synchrony: (1) the excitatory inputs responsible for the transitions to the up state do so simultaneously in several neurons, or (2) lateral transfer of information among NAcc neurons via gap junctions. Although a hypothetical synchrony of inputs may play a role in determining synchrony of up events, gap junctions in the striatum and NAcc can be modulated by a number of neurotransmitters including DA and nitric oxide, as well as cortical inputs (Cepeda et al., 1989; O’Donnell \& Grace, 1993, 1997). Gap junctions can provide a direct route for slow signals, such as up events, to cross from one neuron to another (O'Donnell \& Grace, 1993). In this way, a variety of inputs to the NAcc can modulate both the temporal and the spatial distribution of up events.

\section{DOPAMINE AND INFORMATION PROCESSING IN THE NUCLEUS ACCUMBENS}

The NAcc receives a very dense dopamine (DA) innervation that has been associated with a number of behaviors. For example, DA levels change in the NAcc during feeding and drinking (Yoshida et al., 1992), if the animals have to work for food by leverpressing (Salamone, Cousins, McCullough, Carriero, \& Berkowitz, 1994), during sexual behaviors (Damsma, Pfaus, Wenkstern, Phillips, \& Fibiger, 1992; Pleim, Matochik, Barfield, \& 


\section{UP EVENTS NOT SYNCHRONIZED}

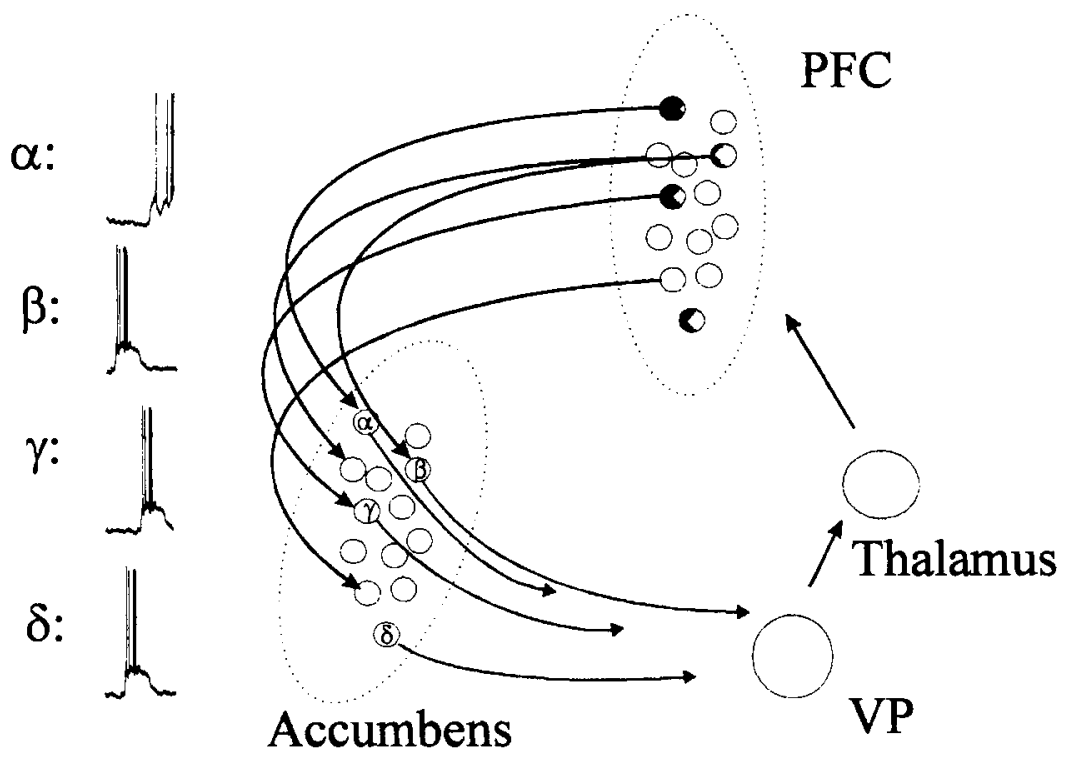

\section{SYNCHRONIZED UP EVENTS}

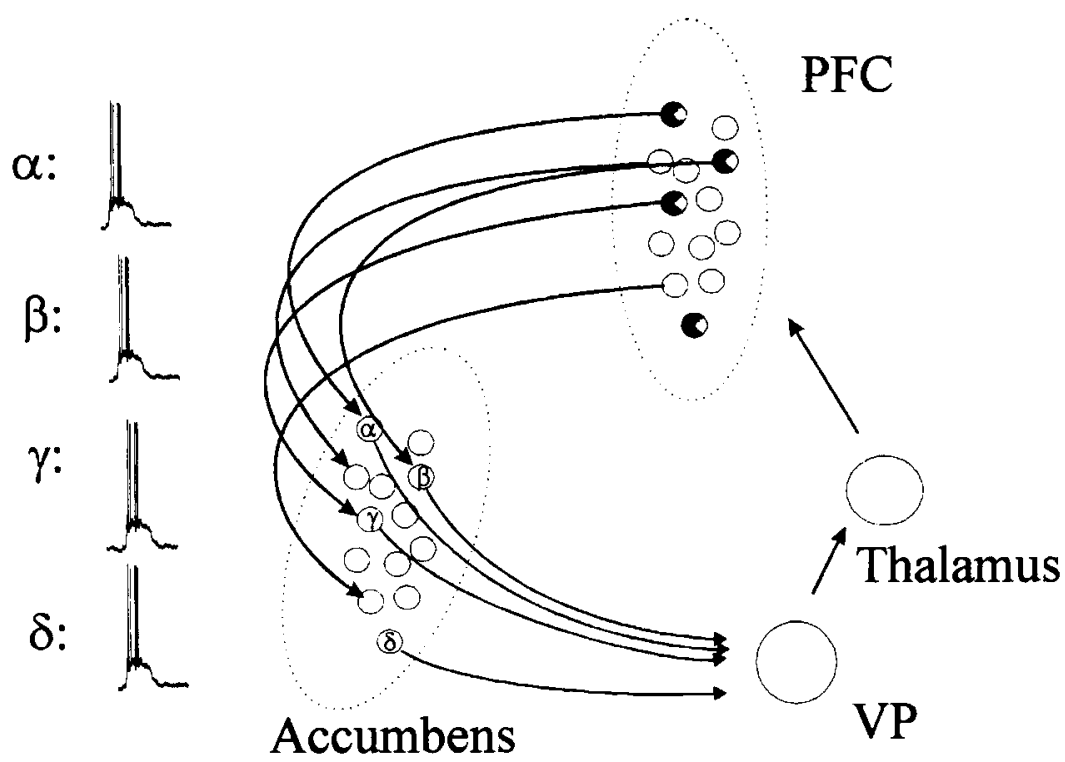

Figure 4. Ensemble coding in the nucleus accumbens requires synchronization of up states in a group of neurons. Upper panel: If up events are not synchronized, accumbens output to the VP will not be time-locked. This is shown as different lengths in the arrows pointing from the accumbens to the VP. Absence of synchronization will result in PFC being activated at different time points (shown as different angles of cone shadows in circles representing PFC neurons). Tracings representing the activity of four hypothetical bistable neurons (labeled with Greek letters) are shown to the left. The hypothetical neurons labeled $\alpha, \beta$, or $\gamma$ receive PFC input during up events and therefore are allowed to send this information down to the VP. Two other hypothetical accumbens neurons receive PFC inputs during the down state (thin open circles) and are not gated. The neuron labeled $\delta$ represents cells that fire in response to other inputs during the up state. Since up events in the nucleus accumbens are not synchronized, PFC neurons will not be simultaneously activated, resulting in failure of establishing a functional ensemble. Lower panel: If up events were synchronized, the simultaneous activity in these four neurons would constitute a functional ensemble, yielding synchronized activation of a distributed set of thalamocortical neurons. 
Auerbach, 1990), and in response to a novel environment (Hooks \& Kalivas, 1994; Rebec, Grabner, Johnson, Pierce, \& Bardo, 1997). Also, latent inhibition depends on DA transmission in the NAcc (Gray et al., 1995), and NAcc cell firing correlates with the timing of cocaine selfadministration (Peoples \& West, 1996). In monkeys, ventral striatal DA is involved in signaling anticipation of reward and behaviorally relevant stimuli (Schultz, 1992).

A common factor in all these actions is that they are associated with appetitive stimuli, which involve increased DA cell activation (Mirenowicz \& Schultz, 1996). DA cells are activated on presentation of reward (Schultz et al., 1992; Schultz, Dayan, \& Montague, 1997). When a conditioned stimulus is paired with the reward, once the association between the signal and the reward has been learned, DA cells will shift their activation to when the conditioned stimulus is presented, rather than with the reward itself (Schultz, 1986; Schultz, Apicella, \& Ljungberg, 1993). This has been interpreted as an involvement of DA in prediction of reward. In summary, DA neurons can be activated by novel unexpected stimuli that attract the attention of the animal (Ljungberg, Apicella, \& Schultz, 1992), by primary reward in the absence of predictive stimuli, or by conditioned stimuli predicting reward (Schultz, 1992). As a result, DA released in the basal ganglia and PFC may be signaling that the current state of ensembles is associated with reward (and therefore worth reinforcing). Ultimately, such control of activity in the NAcc modulates PFC activity, and the appropriate ensemble of PFC neurons will be activated following the NAcc ensemble. Consistent with this hypothesis is the finding that orbitofrontal cortical neurons also activate on expectation of reward or during goal-directed behaviors (Schoenbaum, Chiba, \& Gallagher, 1998).

Although the involvement of the NAcc in reward is well documented, there is a large body of evidence also implicating this brain region in reactions to aversive stimuli (Salamone, Cousins, \& Snyder, 1997). It is well known that DA in the NAcc is elevated by stress (Abercrombie, Keefe, Di Frischia, \& Zigmond, 1989; BertolucciD'Angio, Serrano, Driscoll, \& Scatton, 1990) and during aversive conditioning (Wilkinson et al., 1998). Furthermore, intraaccumbens administration of glutamate antagonists alters avoidance behaviors (Ericson, Svensson, \& Ahlenius, 1990), and NAcc DA is involved in leverpressing to avoid an electric shock (McCullough, Sokolowski, \& Salamone, 1993). However, electrophysiological studies have found that DA neurons in the ventral tegmental area (VTA) increase their firing rate during appetitive, rather than aversive, stimuli (Mirenowicz \& Schultz, 1996), keeping this issue not yet resolved. In any event, the potential participation of NAcc DA in behavioral responses to both appetitive and aversive stimuli may imply an action in the motivational aspects common to both mechanisms (Salamone, 1992). Thus, DA in the NAcc may be involved in acquiring positive and avoiding aversive stimuli (Salamone, 1991).
Despite extensive studies, however, the nature of DA actions in the NAcc at a cellular level is still poorly understood. DA can exert its actions by binding to a variety of receptors, typically grouped in the $D_{1}$ family $\left(D_{1}\right.$ and $\left.D_{5}\right)$ or the $D_{2}$ family $\left(D_{2}, D_{3}\right.$, and $\left.D_{4}\right)$. The actions of DA in the NAcc may depend on which receptor subtype is involved, but the uneven distribution of these receptor subtypes usually complicates the interpretation of studies addressing this issue. Although receptors of both families can be found in postsynaptic membranes of striatal and NAcc neurons, they can be colocalized in a population of neurons and segregated in others. However, the proportion of neurons with colocalized or distributed DA receptor subtypes is intensely debated (Gerfen, 1984; Surmeier, Reiner, Levine, \& Ariano, 1993). DA receptors in output neurons have a variety of actions at postsynaptic level. Administration of DA agonists may result in either depolarization (Akaike, Ohno, Sasa, \& Takaori, 1987; Bernardi, Cherubini, Marciani, Mercuri, \& Stanzione, 1982; Herrling \& Hull, 1980; O’Donnell \& Grace, 1996; Shi, Zheng, Liang, \& Bunney, 1997; Uchimura, Higashi, \& Nishi, 1986) or hyperpolarization (Herrling \& Hull, 1980; Uchimura et al., 1986) in striatal, NAcc, or PFC cells, depending on the recording conditions. Even when cells are depolarized, the threshold for action potential firing is also shifted to more depolarized values (Akaike et al., 1987; O'Donnell \& Grace, 1996). As a consequence, DA reduces the overall probability of firing in NAcc neurons, an action mediated in vitro by $D_{1}$ and $D_{2}$ receptor coactivation (O'Donnell \& Grace, 1996). These findings resemble results of pioneering experiments using in vivo intracellular recordings from PFC neurons showing that DA iontophoretic administration elicits membrane depolarization along with suppression of firing (Bernardi, Calabresi, Mercuri, \& Stanzione, 1984; Bernardi et al., 1982). These results illustrate that DA actions in the NAcc or striatum cannot be simplified to a plus or a minus sign.

Although membrane depolarization or changes in cell excitability have important consequences, DA has other physiological actions that add to the complexity of its effects. These include the modulation of responses to other inputs in its target areas. DA may control the efficacy of synaptic inputs to these regions presynaptically, given the presence of presynaptic DA receptors on glutamatergic terminals. DA receptor activation (pharmacologically by agonists or physiologically by stimulation of DA cells) can modulate synaptic responses to cortical afferent activation in the striatum (Bernardi et al., 1984; Calabresi, Benedetti, Mercuri, \& Bernardi, 1988). In the caudate-putamen $(\mathrm{CPu})$, this is believed to occur through activation of $\mathrm{D}_{2}$ receptors (Brown \& Arbuthnott, 1983; Calabresi et al., 1988); however, in the NAcc, the data are conflicting. Some reports have suggested that $D_{2}$ receptors may reduce the amplitude of EPSPs elicited by activation of PFC afferents in vitro (O'Donnell \& Grace, 1994), whereas others have proposed "atypical" $D_{1}$ receptors (i.e., not linked to adenylate cyclase and requiring 


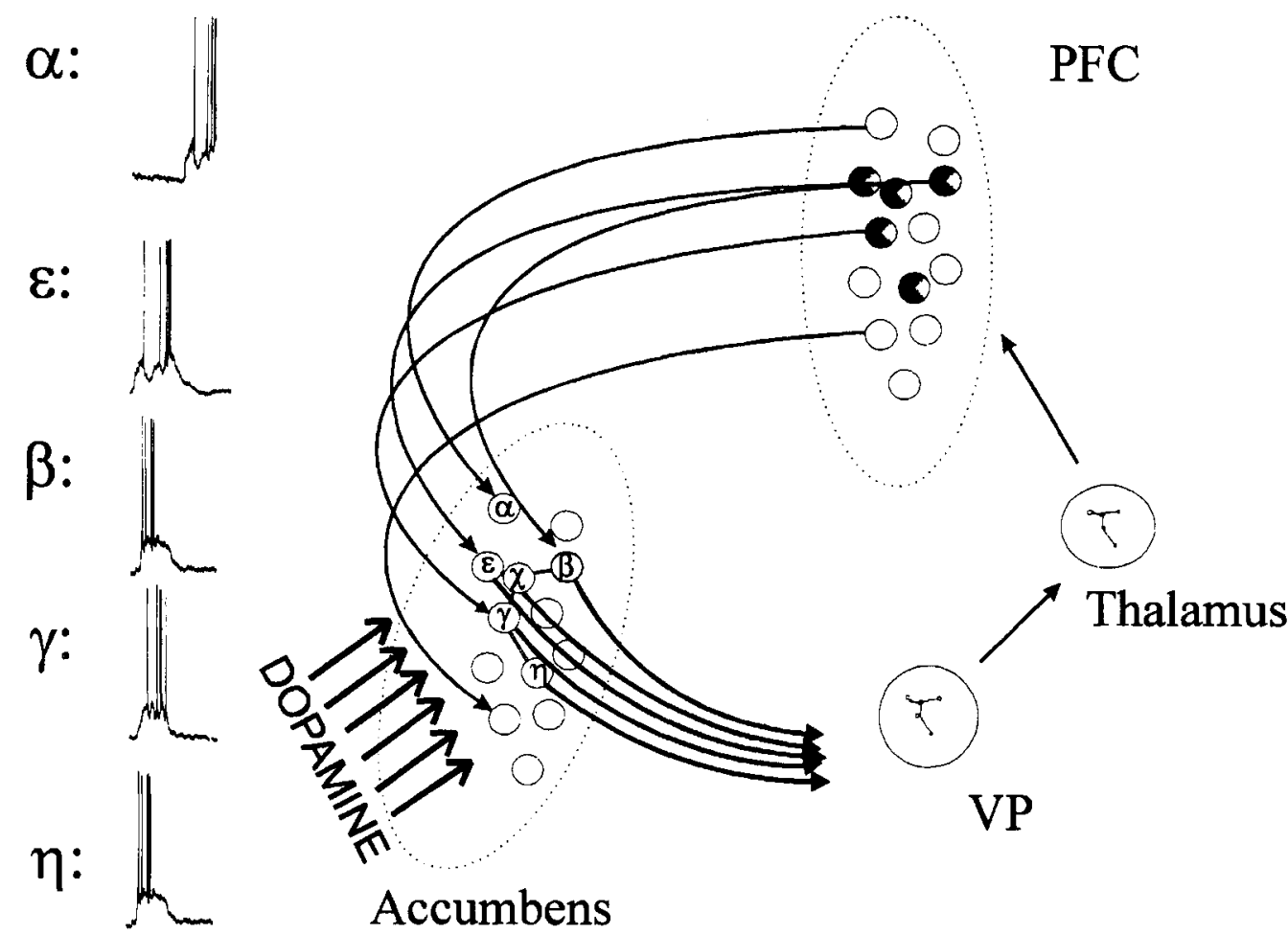

Figure 5. Dopamine contributes to up-state synchronization in accumbens neurons via its control of gap junction permeability and by acting as a state stabilizer. This diagram shows the circuit and representative tracings from five neurons, as shown in Figure 4. Massive DA cell firing results in phasic DA release (thick arrows). In addition to changes in accumbens neuron membrane potential and release of other transmitters (see text), DA controls the cell-to-cell communication via gap junctions. Gap junctions are indicated as parallel lines connecting the circles representing individual neurons in the accumbens. By being permeant at the right time, gap junctions may allow for up events in coupled cells to synchronize. This is represented in four of the five representative traces shown in the left. The nearly simultaneous transitions define a functional ensemble and are transmitted to VP/SN and thalamus, resulting in a specific pattern of thalamocortical activation. The topography of VP neurons inhibited by the ensemble of active NAce neurons is shown with a symbol resembling the spatial location of active NAcc neurons. A similar symbol in the thalamus circle represents the topography of thalamocortical cells disinhibited by this ensemble. The simultaneity of thalamocortical activation is shown as cone shadows in active PFC neurons having the same angle.

exceedingly high doses of antagonists to block the responses) mediating this DA-induced decrease in synaptic response (Harvey \& Lacey, 1996; Nicola, Kombian, \& Malenka, 1996). Interestingly, it has been recently reported that presynaptic control of glutamatergic afferents by DA in the CPu does not affect all stimulated afferents, suggesting that DA may exert some extent of selection among these inputs (Flores-Hernandez, Galarraga, \& Bargas, 1997). Another action of DA bearing on information processing properties in the NAcc and $\mathrm{CPu}$ resides in its control of gap junction permeability (Cepeda et al., 1989; O'Donnell \& Grace, 1993). Gap junctions can serve as low-pass filters, optimized for cell-to-cell transfer of slow signals. Thus, permeant gap junctions could contribute to synchronization of up events among coupled neurons, and DA may be involved in establishing or maintaining neural ensembles by this action (Figure 5).

Whether a neuron is in the up or down state will affect considerably the overall action DA exerts on it. It is tempt- ing to interpret both postsynaptic and presynaptic actions of DA as inhibitory in nature. However, since DA cells fire en bloc in the presence of reward, novelty, or reward-predicting stimuli (Schultz, 1997), an inhibitory action of DA would result in a "freezing" behavioral effect. However, DA and DA agonists are known as behavioral activators instead (Pierce \& Kalivas, 1995; Segal \& Mandell, 1974), even if they are locally administered into the NAcc (Swanson, Heath, Stratford, \& Kelley, 1997). A solution to this paradox may lie in potential different effects of activation of $D_{1}$ or $D_{2}$ receptors depending on the state of the neuron membrane potential. A series of studies from Michael Levine's lab has demonstrated specific DA-glutamate interactions in striatal neurons, depending on the receptor subtype involved. In short, $D_{1}$ receptor activation potentiates NMDA-receptor-mediated responses, whereas $\mathrm{D}_{2}$ receptor activation decreases AMPA-receptor-mediated responses (Cepeda, Colwell, Itri, Chandler, \& Levine, 1998; Levine, Altemus, et al., 
1996; Levine, Li, Cepeda, Cromwell, \& Altemus, 1996). Other lines of evidence also support a link between NMDA and $D_{1}$ receptors; for example, the $D_{1}$-receptorrelated DARPP-32 phosphoprotein has been shown to phosphorylate NMDA receptors (Greengard, Snyder, Fisone, \& Aperia, 1995). Furthermore, tyrosine hydroxylase $(\mathrm{TH})$ terminals in the NAcc are associated with NMDA processes (Gracy \& Pickel, 1996). An interaction between $\mathrm{D}_{1}$ and NMDA receptors may have important functional consequences. During the up state, NMDA receptors are less inactive (their $\mathrm{Mg}^{2+}$ inhibition is partly removed by depolarization); thus, $\mathrm{D}_{1}$ activation may contribute to maintain up events by enhancing longlasting NMDA responses. On the other hand, during the down state $D_{1}$-reinforced NMDA responses will be ineffective, and $\mathrm{D}_{2}$ receptors may be able to shunt moderateamplitude AMPA synaptic responses effectively. In short, by contributing to hold the down state negative and, at the same time, enhancing synaptic responses during the up state, DA can be seen as a "state-stabilizer." If DA is a state stabilizer and DA cells are typically activated en bloc, this will result in a reinforcement of the current ensemble by tagging the distribution of neurons in their up or down state. In other words, DA may contribute to establish a cell ensemble appropriate for a particular context by gap junction modulation and by stabilizing membrane potential states (Figure 5). Neurons driven to their up state by contextual or any other input are kept "ready to go" by this effect of DA. Such an action of DA, which is massively released in relation to rewarding (and perhaps also aversive) stimuli, may add a motivational value to NAcc ensembles controlling PFC function.

Activation of mesoaccumbens, mesocortical, or nigrostriatal systems may also have actions on the ensemble coding of their target areas that are independent of DA. Classical studies have shown EPSPs in CPu, NAcc, and PFC in response to stimulation of DA cells (Calabresi et al., 1990; Hull, Bernardi, \& Buchwald, 1970; Kitai, Sugimori, \& Kocsis, 1976; Mercuri, Calabresi, Stanzione, \& Bernardi, 1985), although a large part of this excitatory component of the response can be abolished by a cortical lesion (C. J. Wilson, Chang, \& Kitai, 1982), suggesting that most of it may be due to activation of fibers of passage. These responses may vary depending on whether the cell is in the up or down state. We have recently shown that VTA stimulation induces transitions to a long-lasting down state, which usually preceded by an EPSP (O'Donnell \& Lewis, 1998). Part of these excitatory responses may be due to non-DA components of these projections. DA cells have been proposed to comprise only a subset of these projections (van der Kooy, 1981); this has been recently substantiated in a monkey study employing several injections of retrograde tracers combined with $\mathrm{TH}$ immunostaining (Williams \& Goldman-Rakic, 1998). Furthermore, DA neurons in culture can establish func- tional glutamatergic synapses (Sulzer et al., 1998). If this proves true in vivo, a burst of action potentials in DA neurons may release DA and glutamate, and this excitatory amino acid will bring the membrane potential of NAcc neurons closer to firing threshold, or even reach it in those NAcc cells in their up state. On the other hand, it would not be sufficient for any significant consequence in cells in the down state. In this way, a hypothetical corelease of glutamate and DA may reinforce the action of DA, resulting in the activation of a selected ensemble of neurons in the NAcc.

\section{DYNAMIC ENSEMBLES IN THE NUCLEUS ACCUMBENS}

The ensembles of active neurons determined by the distribution of neurons in their up state could represent a very effective means of assembling "preset" patterns of striatal activation. In the $\mathrm{CPu}$, motor ensembles could provide a way to reformulate the proposed "motor programs." The concept of motor programs was introduced to account for the presetting of a final common pathway required in ballistic movements (Brooks, 1979; Keele, 1968), but it has been criticized as a "black-box concept", (Alexander, DeLong, \& Crutcher, 1992). Our proposal of ensemble coding in the basal ganglia may provide a means by which preset patterns of activation may be stored, accounting for functions attributed to motor programs while avoiding their computational pitfalls. In the ventral striatum, neural ensembles would be related to cognitive rather than purely motor function. So, they could be the equivalent of a "cognitive program." Ensembles are dynamic; they change moment to moment depending on contextual variations and to adjust accordingly the behavioral output. Behavioral experiments based on reward in monkeys have suggested that the ventral striatum can keep track of progress of learned behavioral sequences leading to reward (Shidara et al., 1998). Release of DA by mesoaccumbens terminals may reinforce cognitive ensembles in the same way nigrostriatal DA may reinforce motor ensembles.

\section{IMPLICATIONS FOR SCHIZOPHRENIA AND PARKINSON'S DISEASE}

Current hypotheses on schizophrenia pathophysiology are attempting to bring together disparate findings, such as hypofrontality, alteration in DA systems, and a hippocampal deficit (O'Donnell \& Grace, 1998). We have speculated that the basal ganglia are a brain region in which most of the systems implicated in schizophrenia may converge. In particular, the integration of inputs from the hippocampus, amygdala, and PFC in the NAcc makes it a likely candidate to be at the center stage of any valid model. Indeed, an alteration in ensemble coding in the NAcc may be a consequence of the primary distur- 
bance in schizophrenia, be it a hippocampal or PFC alteration. An increase in phasic firing of DA cells (Grace, 1991) along with a deficient hippocampal input providing erroneous contextual information could result in the establishment of inappropriate ensembles. The abnormally large DA release would tag and reinforce such inadequate ensembles. A failure in establishing contextually appropriate ensembles may result in activation of improper units in the PFC - this being likely to underlie symptoms such as hallucinations or delusions (positive symptoms) that have been correlated with hippocampal dysfunction and increased DA activity (Davis, Kahn, Ko, \& Davidson, 1991; O’Donnell \& Grace, 1998). Conversely, antipsychotics would contribute to the reinstatement of some extent of ensemble coding. All clinically effective antipsychotics are DA antagonists. They exert their actions over repeated administration by inducing depolarization block in DA cells (Grace, Bunney, Moore, $\&$ Todd, 1997). As a result, although the cortical impairments would still be present, the increased phasic DA release that reinforces the inappropriate ensembles would be prevented.

Parkinson's disease (Pd), on the other hand, could be the expression of a failure in the reinforcement of motor ensembles due to low DA levels. A consequence of the absence of adequate ensemble coding would be an altered sequence of motor commands. The attenuation of symptoms by L-DOPA replacement therapy may be the result of DA levels restored to a point sufficient to restore motor ensemble coding. However, since the increased DA levels are the result of exogenous administration rather than derived from DA cell firing, the ensemble sequences reinforced may not be altogether appropriate. They will not follow the temporal pattern normally induced by DA cell firing. Consistent with this hypothesis is the observation that medicated Pd patients exhibit impaired motor timing (Harrington, Haaland, \& Hermanowicz, 1998). A disruption in this delicate balance may result in inappropriate motor sequences being enabled. In the long run, this may underscore the appearance of LDOPA-induced dyskinesias (Marsden, 1994). Another side effect of L-DOPA therapy is the development of psychotic episodes. These may be the consequence of excessive and functionally inappropriate levels of DA in limbic areas (including the NAcc), tagging inappropriate cognitive ensembles.

\section{CONCLUSION}

In summary, information processing in the NAcc may be seen as a changing ensemble of active neurons, which are simultaneously exhibiting their membrane potentials in their active (up) state. The spatial distribution of active neurons constituting these ensembles is under the control of a variety of inputs. DA selects the appropriate ongoing ensembles according to their behavioral relevance; this could be either appetitive or aversive, thus requiring ensemble reinforcement or ensemble avoidance. Either excessive or deficient DA levels may alter the process of ensemble coding in the NAcc and striatum, causing an alteration in PFC function.

\section{REFERENCES}

Abercrombie, E. A., Keefe, K. A., Di Frischia, D. A., \& Zigmond, M. J. (1989). Differential effect of stress on in vivo dopamine release in striatum, nucleus accumbens and medial prefrontal cortex. Journal of Neurochemistry, 52, 1655-1658.

AKAIKE, A., OHNO, Y., SASA, M., \& TAKAORI, S. (1987). Excitatory and inhibitory effects of dopamine on neural activity of the caudate nucleus neurons in vitro. Brain Research, 418, 262-272.

Alexander, G. E., Delong, M. R., \& Crutcher, M. D. (1992). Do cortical and basal ganglionic motor areas use "motor programs" to control movement? Behavioral \& Brain Sciences, 15, 656-665.

AnNett, L. E., McGregor, A., \& Robins, T. W. (1989). The effects of ibotenic acid lesions of the nucleus accumbens on spatial learning and extinction in the rat. Behavioural Brain Research, 31, 231-242.

Apicella, P., LuUngrerg, T., Scarnati, E., \& Schultz, W. (1991). Responses to reward in monkey dorsal and ventral striatum. Experimental Brain Research, 85, 491-500.

Bernardi, G., Calabresi, P., Mercuri, N., \& Stanzione, P. (1984). Dopamine decreases the amplitude of excitatory post-synaptic potentials in rat striatal neurones. In J. S. McKenzie, R. E. Kemm, \& L. N. Wilcock (Eds.), The basal ganglia: Structure and function (pp. 161-171). New York: Plenum.

Bernardi, G., Cherubini, E., Marciani, M. G., Mercuri, N., \& StANZIONE, P. (1982). Responses of intracellularly recorded cortical neurons to the iontophoretic application of dopamine. Brain Research, 245, 268-274.

Bertolucci-D' Angio, M., Serrano, A., Driscoll, P., \& Scatton, B. (1990). Involvement of mesocorticolimbic dopaminergic systems in emotional states. Progress in Brain Research, 85, 405-417.

Brooks, V. B. (1979). Motor programs revisited. In R. E. Talbott \& D. R. Humphrey (Eds.), Posture and movement (pp. 13-49). New York: Raven.

Brown, J. R., \& ARBUthNott, G. W. (1983). The electrophysiology of dopamine $\left(D_{2}\right)$ receptors: A study of the actions of dopamine on corticostriatal transmission. Neuroscience, 10, 349-355.

Calabresi, P., Benedetti, M., Mercuri, N. B., \& Bernardi, G. (1988). Endogenous dopamine and dopaminergic agonists modulate synaptic excitation in neostriatum: Intracellular studies from naive and catecholamine-depleted rats. Neuroscience, 27, 145-157.

Calabresi, P., Mercuri, N., Stefani, A., \& Bernardi, G. (1990). Synaptic and intrinsic control of membrane excitability of neostriatal neurons. I. An in vivo analysis. Journal of Neurophysiology, 63, 651-662.

Cepeda, C., Colwell, C. S., Itri, J. N., Chandler, S. H., \& Levine, M. S. (1998). Dopaminergic modulation of NMDA-induced whole cell currents in neostriatal neurons in slices: Contribution of calcium conductances. Journal of Neurophysiology, 79, 82-94.

Cepeda, C., Walsh, J. P., Hull, C. D., Howard, S. G., Buchwald, N. A., \& Levine, M. S. (1989). Dye-coupling in the neostriatum of the rat. I. Modulation by dopamine-depleting lesions. Synapse, 4 , 229-237.

Chu, B., \& Kelley, A. E. (1992). Potentiation of reward-related responding by psychostimulant infusion into nucleus accumbens: Role of dopamine receptor subtypes. Psychobiology, 20, 153-162.

Clifton, P. G., \& Somerville, E. M. (1994). Disturbance of meal patterning following nucleus accumbens lesions in the rat. Brain Research, 667, 123-128.

Damsma, G., Pfaus, J. G., Wenkstern, D., Phillips, A. G., \& Fibiger, H. C. (1992). Sexual behavior increases dopamine transmission in the nucleus accumbens and striatum of male rats: Comparison with novelty and locomotion. Behavioral Neuroscience, 106, 181-191.

Davis, K. L., KAHN, R. S., Ko, G., \& Davidson, M. (1991). Dopamine in schizophrenia: A review and reconceptualization. American Journal of Psychiatry, 148, 1474-1486.

Eichenbaum, H., Wiener, S. I., Shapiro, M. L., \& Cohen, N. J. 
(1989). The organization of spatial coding in the hippocampus: A study of neural ensemble activity. Journal of Neuroscience, 9, 27642775.

Ericson, E., Svensson, T. H., \& Ahlenius, S. (1990). Loss of discriminative avoidance behavior by local application of kynurenic acid into the nucleus accumbens of the rat. Pharmacology, Biochemistry \& Behavior, 37, 843-845.

FINCH, D. M. (1996). Neurophysiology of converging synaptic inputs from the rat prefrontal cortex, amygdala, midline thalamus, and hippocampal formation onto single neurons of the caudate/putamen and nucleus accumbens. Hippocampus, 6, 495-512.

Floresco, S. B., Seamans, J. K., \& Phillips, A. G. (1997). Selective roles for hippocampal, prefrontal cortical, and ventral striatal circuits in radial-arm maze tasks with or without a delay. Journal of Neuroscience, 17, 1880-1890.

Flores-Hernandez, J., Galarraga, E., \& Bargas, J. (1997). Dopamine selects glutamatergic inputs to neostriatal neurons. Synapse, 25 , 185-195.

FUSTER, J. M. (1997). The prefrontal cortex: Anatomy, physiology, and neuropsychology of the frontal lobe. New York: Lippincott-Raven.

Gal, G., Joel, D., Gusak, O., Feldon, J., \& Weiner, I. (1997). The effects of electrolytic lesion to the shell subterritory of the nucleus accumbens on delayed non-matching-to-sample and four-arm baited eigth-arm radial maze tasks. Behavioral Neuroscience, 111, 92-103.

GERFEN, C. R. (1984). The neostriatal mosaic: Compartmentalization of corticostriatal input and striatonigral output systems. Nature, 311, 461-464.

Grace, A. A. (1991). Phasic versus tonic dopamine release and the modulation of dopamine system responsivity: A hypothesis for the etiology of schizophrenia. Neuroscience, 41, 1-24.

Grace, A. A., Bunney, B. S., Moore, H., \& Todo, C. L. (1997). Dopamine cell depolarization block as a model for the therapeutic actions of antipsychotic drugs. Trends in Neurosciences, 20, 31-37.

GracY, K. N., \& PTCKEl, V. M. (1996). Ultrastructural immunocytochemical localization of the $N$-methyl- $D$-aspartate receptor and tyrosine hydroxylase in the shell of the rat nucleus accumbens. Brain Research, 739, 169-181.

Gray, J. A., Joseph, M. H., Hemsley, D. R., Young, A. M. J., Warburton, E. C., Boulenguez, P., Grigoryan, G. A., Peters, S. L., Rawlins, J. N. P., Taib, C.-T., Yee, B. K., Cassaday, H., Weiner, I., Gal, G., Gusak, O., Joel, D., Shadach, E., Shalev, U., TarRASCH, R., \& FELDON, J. (1995). The role of mesolimbic dopaminergic and retrohippocampal afferents to the nucleus accumbens in latent inhibition: Implications for schizophrenia. Behavioural Brain Research, 71, 19-31.

GraYBIEL, A. M. (1997). The basal ganglia and cognitive pattern generators. Schizophrenia Bulletin, 23, 459-469.

Greengard, P., Snyder, G., Fisone, G., \& Aperia, A. (1995). Interactions of signal transduction pathways in the nervous system. In D. Ottoson, T. Bartfai, T. Hökfelt, \& K. Fuxe (Eds.), Challenges and perspectives in neuroscience (pp. 3-26). Tarrytown, NY: Elsevier.

Groenewegen, H. J., \& BerendSE, H. W. (1994). Anatomical relationships between the prefrontal cortex and the basal ganglia in the rat. In A.-M. Thierry (Ed.), Motor and cognitive functions of the prefrontal cortex (pp. 51-77). Berlin: Springer-Verlag.

Groenewegen, H. J., Berendse, H. W., Meredith, G. E., Haber, S. N., Voorn, P., Wolters, J. G., \& Lohman, A. H. M. (1991). Functional anatomy of the ventral, limbic system-innervated striatum. In P. Willner \& J. Scheel-Kruger (Eds.), The mesolimbic dopamine system: From motivation to action (pp. 19-59). New York: Wiley.

Harrington, D. L., HaAland, K. Y., \& Hermanowicz, N. (1998). Temporal processing in the basal ganglia. Neuropsychology, 12, 3-12.

HaRveY, J., \& LaCEY, M. G. (1996). Endogenous and exogenous dopamine depress EPSCs in rat nucleus accumbens in vitro via $D_{1}$ receptor activation. Journal of Physiology, 492, 143-154.

HERRLING, P. L., \& HulL, C. D. (1980). Iontophoretically applied dopamine depolarizes and hyperpolarizes the membrane of cat caudate neurons. Brain Research, 192, 441-462

HooKs, M. S., \& Kalıvas, P. W. (1994). Involvement of dopamine and excitatory amino acid transmission in novelty-induced motor activity. Journal of Pharmacology \& Experimental Therapeutics, 269, 976-988.

Hooks, M. S., \& Kalivas, P. W. (1995). The role of mesoaccumbenspallidal circuitry in novelty-induced behavioral activation. Neuroscience, 64, 587-597.

Hull, C. D., BerNaRdi, G., \& Buchwald, N. A. (1970). Intracellular responses of caudate neurons to brain stem stimulation. Brain Research, 22, 163-179.

KEELE, S. W. (1968). Movement control in skilled motor performance. Psychological Bulletin, 70, 387-403.

Kitai, S. T., Sugimori, H., \& KoCsis, J. (1976). Excitatory nature of dopamine in the nigro-caudate pathway. Experimental Brain Research, 24, 351-363.

KODSI, M. H., \& SWERDLOW, N. R. (1997). Reduced prepulse inhibition after electrolytic lesions of nucleus accumbens subregions in the rat. Brain Research, 773, 45-52.

Levine, M. S., Altemus, K. L., Cepeda, C., Cromwell, H. C., Crawford, C., ARiano, M. A., Drago, J., Sibley, D. R., \& Westphal, H. (1996). Modulatory actions of dopamine on NMDA receptormediated responses are reduced in $\mathrm{D}_{1 \mathrm{~A}}$-deficient mutant mice. Jour nal of Neuroscience, 16, 5870-5882.

Levine, M. S., Li, Z., Cepeda, C., Cromwell, H. C., \& Altemus, K. L. (1996). Neuromodulatory actions of dopamine on synapticallyevoked neostriatal responses in slices. Synapse, 24, 65-78.

Lunngberg, T., APicella, P., \& Schultz, W. (1992). Responses of monkey dopamine neurons during learning of behavioral reactions. Journal of Neurophysiology, 67, 145-163.

Maldonado-IrizarRY, C. S., \& Kelley, A. E. (1994). Differential behavioral effects following microinjection of an NMDA antagonist into nucleus accumbens subregions. Psychopharmacology, 116, 65-72.

Maldonado-IrizarRY, C. S., \& Kelley, A. E. (1995). Excitatory amino acid receptors within nucleus accumbens subregions differentially mediate spatial learning in the rat. Behavioural Pharmacology, 6, 527-539.

Maldonado-Iruzarry, C. S., Swanson, C. J., \& Kelley, A. E. (1995) Glutamate receptors in the nucleus accumbens shell control feeding behavior via the lateral hypothalamus. Journal of Neuroscience, 15, 6779-6788.

MarSDEN, C. D. (1994). Problems with long-term levodopa therapy for Parkinson's disease. Clinical Neuropharmacology, 17, S32-S44.

McCullough, L. D., Sokolowski, J. D., \& Salamone, J. D. (1993). A neurochemical and behavioral investigation of the involvement of nucleus accumbens dopamine in instrumental avoidance. Neuroscience, 52, 919-925.

Mercuri, N., Calabresi, P., Stanzione, P., \& Bernardi, G. (1985) Electrical stimulation of mesencephalic cell groups (A9-A10) produces monosynaptic excitatory potentials in rat frontal cortex. Brain Research, 338, 192-195.

MiRENOWICZ, J., \& SCHULTZ, W. (1996). Preferential activation of midbrain dopamine neurons by appetitive rather than aversive stimuli. Nature, 379, 449-451.

Mogenson, G. J., \& WU, M. (1991a). Effects of administration of dopamine $\mathrm{D}_{2}$ agonist quinpirole on exploratory locomotion. Brain Research, 551, 216-220.

Mogenson, G. J., \& Wu, M. (1991b). Quinpirole to the accumbens reduces exploratory amphetamine-elicited locomotion. Brain Research Bulletin, 27, 743-746.

Nicola, S. M., Kombian, S. B., \& Malenka, R. C. (1996). Psychostimulants depress excitatory synaptic transmission in the nucleus accumbens via presynaptic D1-like dopamine receptors. Journal of Neuroscience, 16, 1591-1604.

O'Donnell, P., \& Grace, A. A. (1993). Dopaminergic modulation of dye coupling between neurons in the core and shell regions of the nucleus accumbens. Journal of Neuroscience, 13, 3456-3471.

O'DONNELL, P., \& GRACE, A. A. (1994). Tonic $\mathrm{D}_{2}$-mediated attenuation of cortical excitation in nucleus accumbens neurons recorded in vitro. Brain Research, 634, 105-112.

O'Donnell, P., \& Grace, A. A. (1995). Synaptic interactions among 
excitatory afferents to nucleus accumbens neurons: Hippocampal gating of prefrontal cortical input. Journal of Neuroscience, 15, 3622-3639.

O'Donnell, P., \& GRace, A. A. (1996). Dopaminergic reduction of excitability in nucleus accumbens neurons recorded in vitro. $\mathrm{Neu}$ ropsychopharmacology, 15, 87-98.

O'Donnell, P., \& GRACE, A. A. (1997). Cortical afferents modulate striatal gap junction permeability via nitric oxide. Neuroscience, $\mathbf{7 6}$, $1-5$.

O'Donnell, P., \& Grace, A. A. (1998). Dysfunctions in multiple interrelated systems as the neurobiological bases of schizophrenic symptom clusters. Schizophrenia Bulletin, 24, 267-283

O'Donnell, P., Lavín, A., Enquist, L. W., Grace, A. A., \& Card, J. P. (1997). Interconnected parallel circuits between rat nucleus accumbens and thalamus revealed by retrograde transynaptic transport of pseudorabies virus. Journal of Neuroscience, 17, 2143-2167.

O'DoNNELL, P., \& LEWIS, B. (1998, July). Dopaminergic control of prefrontal cortical activity: Effect of VTA stimulation on bistable membrane potential of prefrontal cortical pyramidal neurons. Paper presented at the Dopamine 98 Meeting, Strasbourg.

Pennartz, C. M. A., Groenewegen, H. J., \& Lopes da Silva, F. H (1994). The nucleus accumbens as a complex of functionally distinct neuronal ensembles: An integration of behavioural, electrophysiological and anatomical data. Progress in Neurobiology, 42, 719-761.

Peoples, L. L., \& West, M. O. (1996). Phasic firing of single neurons in the rat nucleus accumbens correlated with the timing of intravenous cocaine self-administration. Journal of Neuroscience, $\mathbf{1 5}$ 3459-3473

Pierce, R. C., \& Kalivas, P. W. (1995). Amphetamine produces sensitized increases in locomotion and extracellular dopamine preferentially in the nucleus accumbens shell of rats administered repeated cocaine. Journal of Pharmacology \& Experimental Therapeutics, 275, 1019-1029.

Pleim, E. T., Matochik, J. A., Barfield, R. J., \& Auerbach, S. B. (1990). Correlation of dopamine release in the nucleus accumbens with masculine sexual behavior in rats. Brain Research, 524, 160-163.

Ploeger, G. E., Willemen, A. P. M., \& Cools, A. R. (1991). Role of the nucleus accumbens in social memory in rats. Brain Research Bulletin, 26, 23-27.

Prinssen, E. P. M., Balestra, W., Bemelmans, F. F. J., \& Cools, A. R. (1994). Evidence for a role of the shell of the nucleus accumbens in oral behavior of freely moving rats. Journal of Neuroscience, 14, $1555-1562$.

READING, P. J., \& DUNNETT, S. B. (1991). The effects of excitotoxic lesions of the nucleus accumbens on a matching to position task. $B e$ havioural Brain Research, 46, 17-29.

Rebec, G. V., Grabner, C. P., Johnson, M., Pierce, R. C., \& Bardo, M. T. (1997). Transient increases in catecholaminergic activity in medial prefrontal cortex and nucleus accumbens shell during novelty. Neuroscience, 76, 707-714.

SALAMONE, J. D. (1991). Behavioral pharmacology of dopamine systems: a new synthesis. In P. Willner \& J. Scheel-Krüger (Eds.), The mesolimbic dopamine system: From motivation to action (pp. 599-613). New York: Wiley.

SALAMONE, J. D. (1992). Complex motor and sensorimotor functions of striatal and accumbens dopamine: Involvement in instrumental behavior processes. Psychopharmacology, 107, 160-174.

Salamone, J. D., Cousins, M. S., McCullough, L. D., Carriero, D. L., \& BERKowitz, R. J. (1994). Nucleus accumbens dopamine release increases during instrumental lever pressing for food but not free food consumption. Pharmacology, Biochemistry \& Behavior, 49, 25-31

Salamone, J. D., Cousins, M. S., \& SNyder, B. J. (1997). Behavioral functions of nucleus accumbens dopamine: Empirical and conceptual problems with the anhedonia hypothesis. Neuroscience \& Biobehavioral Reviews, 21, 341-359.

Schoenbaum, G., Chiba, A. A., \& Gallagher, M. (1998). Orbitofrontal cortex and basolateral amygdala encode expected outcomes during learning. Nature Neuroscience, 1, 155-159.

SCHULTZ, W. (1986). Responses of midbrain dopamine neurons to be- havioral trigger stimuli in the monkey. Journal of Neurophysiology, 56, 1439-1461.

ScHULTZ, W. (1992). Activity of dopamine neurons in the behaving primate. Seminars in the Neurosciences, 4, 129-138.

SCHULTZ, W. (1997). Dopamine neurons and their role in reward mechanisms. Current Opinion in Neurobiology, 7, 191-197.

Schultz, W., Apicella, P., \& LuUngberg, T. (1993). Responses of monkey dopamine neurons to reward and conditioned stimuli during successive steps of learning a delayed response task. Journal of Neuroscience, 13, 900-913.

Schultz, W., Apicella, P., Scarnati, E., \& Ljungberg, T. (1992). Neuronal activity in monkey ventral striatum related to the expectation of reward. Journal of Neuroscience, 12, 4595-4610.

Schultz, W., Dayan, P., \& Montague, P. R. (1997). A neural substrate of prediction and reward. Science, 275, 1593-1599.

Seamans, J. K., \& Phillips, A. G. (1994). Selective memory impairments produced by transient lidocaine-induced lesions of the nucleus accumbens. Behavioral Neuroscience, 108, 456-468.

SEGAL, D. S., \& MANDELL, A. J. (1974). Long-term administration of $d$-amphetamine: Progressive augmentation of motor activity and stereotypy. Pharmacology, Biochemistry \& Behavior, 2, 249-255.

Shi, W.-X., Zheng, P., Liang, X.-F., \& Bunney, B. S. (1997). Characterization of dopamine-induced depolarization of prefrontal cortical neurons. Synapse, 26, 415-422.

Shidara, M., Aigner, T. G., \& Richmond, B. J. (1998). Neuronal signals in the monkey ventral striatum related to progress through a predictable series of trials. Journal of Neuroscience, 18, 2613-2625.

Solomon, P. R., \& Staton, D. M. (1982). Differential effects of microinjections of $d$-amphetamine into the nucleus accumbens or the caudate-putamen on the rat's ability to ignore an irrelevant stimulus. Biological Psychiatry, 17, 743-745.

Stern, C., \& Passingham, R. (1994). The nucleus accumbens in monkeys (Macaca fascicularis): I. The organization of behavior. Behavioural Brain Research, 61, 9-21.

Sulzer, D., Joyce, M. P., Lin, L., Geldwert, D., Haber, S. N., \& HATTORI, T. (1998). Dopamine neurons make glutamatergic synapses in vitro. Journal of Neuroscience, 18, 4588-4602.

Surmeier, D. J., Reiner, A., Levine, M. S., \& Ariano, M. A. (1993). Are neostriatal dopamine receptors co-localized? Trends in Neurosciences, 16, 299-305

Swanson, C. J., Heath, S., Stratford, T. R., \& Kelley, A. E. (1997) Differential behavioral responses to dopaminergic stimulation of nucleus accumbens subregions in the rat. Pharmacology, Biochemistry \& Behavior, 58, 933-945.

UChImURA, N., Higashi, H., \& Nishi, S. (1986). Hyperpolarizing and depolarizing actions of dopamine via D-1 and D-2 receptors on nucleus accumbens neurons. Brain Research, 375, 368-372.

VAN DER KOOY, D. (1981). Is there a nondopaminergic nigrostriatal pathway? Neuroscience, 6, 345-357.

WAN, F.-J., GEYeR, M. A., \& SWerdlow, N. R. (1994). Accumbens D, modulation of sensorimotor gating in rats: Assessing anatomical localization. Pharmacology, Biochemistry \& Behavior, 49, 155-163.

WAN, F.-J., \& SwERdLow, N. R. (1993). Intra-accumbens infusion of quinpirole impairs sensorimotor gating of acoustic startle in rats. Psychopharmacology, 113, 103-109.

WAN, F.-J., \& SWERDLOW, N. R. (1996). Sensorimotor gating in rats is regulated by different dopamine-glutamate interactions in the nucleus accumbens core and shell subregions. Brain Research, $\mathbf{7 2 2}$, $168-176$.

Westriook, R. F., Good, A. J., \& Kiernan, M. J. (1997). Microinjection of morphine into the nucleus accumbens impairs contextual learning in rats. Behavioral Neuroscience, 111, 996-1013.

Wilkinson, L. S., Humby, T., Killcross, A. S., Torres, E. M. EveritT, B. J., \& RobBins, T. W. (1998). Dissociations in dopamine release in medial prefrontal cortex and ventral striatum during the acquisition and extinction of classical aversive conditioning in the rat. European Journal of Neuroscience, 10, 1019-1026.

Williams, S. M., \& Goldman-RAKIC, P. S. (1998). Widespread origin of the primate mesofrontal dopamine system. Cerebral Cortex, 8 , $321-345$ 
Wilson, C. J., Chang, H. T., \& Kitai, S. T. (1982). Origins of postsynaptic potentials evoked in identified rat neostriatal neurons by stimulation in substantia nigra. Experimental Brain Research, 45, 157-167.

WILsON, C. J., \& Groves, P. M. (1981). Spontaneous firing patterns of identified spiny neurons in the rat neostriatum. Brain Research, 220, 67-80.

WILSON, C. J., \& KAWAGUCHI, Y. (1996). The origins of two-state spontaneous membrane potential fluctuations of neostriatal spiny neurons. Journal of Neuroscience, 16, 2397-2410.

WiLson, M. A., \& McNaughton, B. L. (1993). Dynamics of the hippocampal ensemble code for space. Science, 261, 1055-1058.

Yoshida, M., Yokoo, H., Mizoguchi, K., KaWahara, H., Tsuda, A.,
NishiKaWA, T., \& TANAKA, M. (1992). Eating and drinking cause increased dopamine release in the nucleus accumbens and ventral tegmental area in the rat: Measurement by in vivo microdialysis. $\mathrm{Neu}$ roscience Letters, 139, 73-76.

Zahm, D. S., Williams, E., \& Wohltmann, C. (1996). Ventral striatopallidothalamic projection: IV. Relative involvements of neurnchemically distinct subterritories in the ventral pallidum and adjacent parts of the rostroventral forebrain. Journal of Comparative Neurology, 364, 340-362.

(Manuscript received July 6, 1998;

revision accepted for publication September 17, 1998.) 